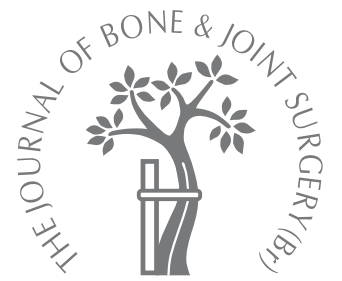

B. J. Berli,

D. Schäfer,

E. W. Morscher

From the

Orthopaedic

Department,

University of Basel,

Basel, Switzerland

B. J. Berli, MD,

Orthopaedic Surgeon,

Research Fellow

D. Schäfer, MD,

Orthopaedic Surgeon

Orthopaedic Department

E. W. Morscher, MD,

Orthopaedic Surgeon,

Professor Emeritus

Laboratory for Orthopaedic

Biomechanics

University of Basel, Felix

Platter-Spital, CH-4012 Basel,

Switzerland.

Correspondence should be sent to Dr B. J. Berli; e-mail: berli.bernhard@tiscali.ch

(C)2005 British Editorial

Society of Bone and

Joint Surgery

doi:10.1302/0301-620X.87B7.

$16149 \$ 2.00$

$J$ Bone Joint Surg $[\mathrm{Br}]$

2005;87-B:928-33.

Received 22 March 2004;

Accepted after revision

24 November 2004

\title{
Ten-year survival of the MS-30 matt-surfaced cemented stem
}

The Morscher-Spotorno (MS-30) femoral stem is a stainless-steel, straight, threedimensionally tapered, collarless implant for cemented fixation in total hip replacement.

We report the results at ten years of a consecutive series of 124 total hip replacements in 121 patients with the matt-surfaced MS-30 stem and an alumina ceramic head of 28-mm diameter. All the stems were fixed with Palacos bone cement with gentamicin using a modern cementing technique. They were combined with an uncemented, press-fit cup. The mean period of observation was 10.2 years $(8.3$ to 12.1$)$ and no patient was lost to followup. Twenty-seven patients $(22 \%)$ died with the implant in situ. Nine could only be interviewed by telephone. We included 85 patients with 88 hips in the clinical and radiological follow-up examinations.

None of the stems or cups had been revised. The Harris hip score was excellent or good in $97 \%$ (85 hips) and moderate in $3 \%$ (three hips). Radiologically, six hips $(6.8 \%)$ had osteolysis adjacent to the stem, mostly in Gruen zone 7. Twenty (22.7\%) showed one or more radiolucent lines. Twenty-two stems (25\%) had subsided by $2 \mathrm{~mm}$ to $5 \mathrm{~mm}$. In these cases two showed osteolysis $(9.1 \%)$ with subsidence and four without $(6.1 \%)$. Radiolucent lines were seen in seven with migration $(31.8 \%)$ and in 13 without $(19.7 \%)$. No infections and no acetabular osteolysis were observed.

The clinical results were excellent with survivorship after ten years of $100 \%$ and only a slightly statistically non-significant higher rate of osteolysis and radiolucency in cases of subsidence.

The Morscher-Spotorno femoral stem (MS-30; Zimmer Ltd, Winterthur, Switzerland; Fig. 1), is manufactured from stainless steel and is designed for cemented fixation in total hip replacement (THR). The primary goal for its development was to give an optimal cement mantle, ${ }^{1}$ which is one of the most important factors in the longevity of a cemented femoral stem (Fig. 2). The quality of the cement mantle depends upon the design of the implant, its surface finish and the characteristics of the material, as well as on the operative technique. In the past, inadequate cementing techniques have been the main cause of the high rate of aseptic loosening. ${ }^{2}$ The causes of failure of cemented femoral stems are insufficient medial support, ${ }^{3}$ an inadequate cement mantle with metal-bone contact, ${ }^{4}$ poor cement-bone interdigitation ${ }^{2}$ and a suboptimal position of the stem..$^{5-7}$

Laboratory and clinical work suggests that the optimum dimensions of a cement mantle are asymmetrical. It should be thicker in the region through which the main forces are transmitted, i.e. in zones 7, 3 and 5 of Gruen et al. ${ }^{6}$ Overall, the thickness of the mantle around the stem should not be less than $2 \mathrm{~mm} .^{3,8}$

The MS-30 stem is tapered distally in three dimensions and functions in a press-fit manner. The selected stem is undersized in comparison with the prepared medullary canal in order to provide the correct space for cement between the implant and bone. The thickness of the cement mantle must be considered during preoperative planning. The edges of the stem are rounded in order to minimise the creation of stress risers within the cement and flanges on the proximolateral part of the prosthesis increase its rotational stability, which is further improved by a high neck resection ${ }^{9,10}$ at an angle of $30^{\circ}$ to the horizontal (Fig. 2). An integral part of the system is the centraliser, which helps to position the component distally in order to avoid metal-bone contact and malalignment. ${ }^{1}$ However, a varus position of the stem is initially avoided by lateral reaming of the medullary canal.

We wished to establish the clinical rate of survival of the MS-30 femoral stem with the 


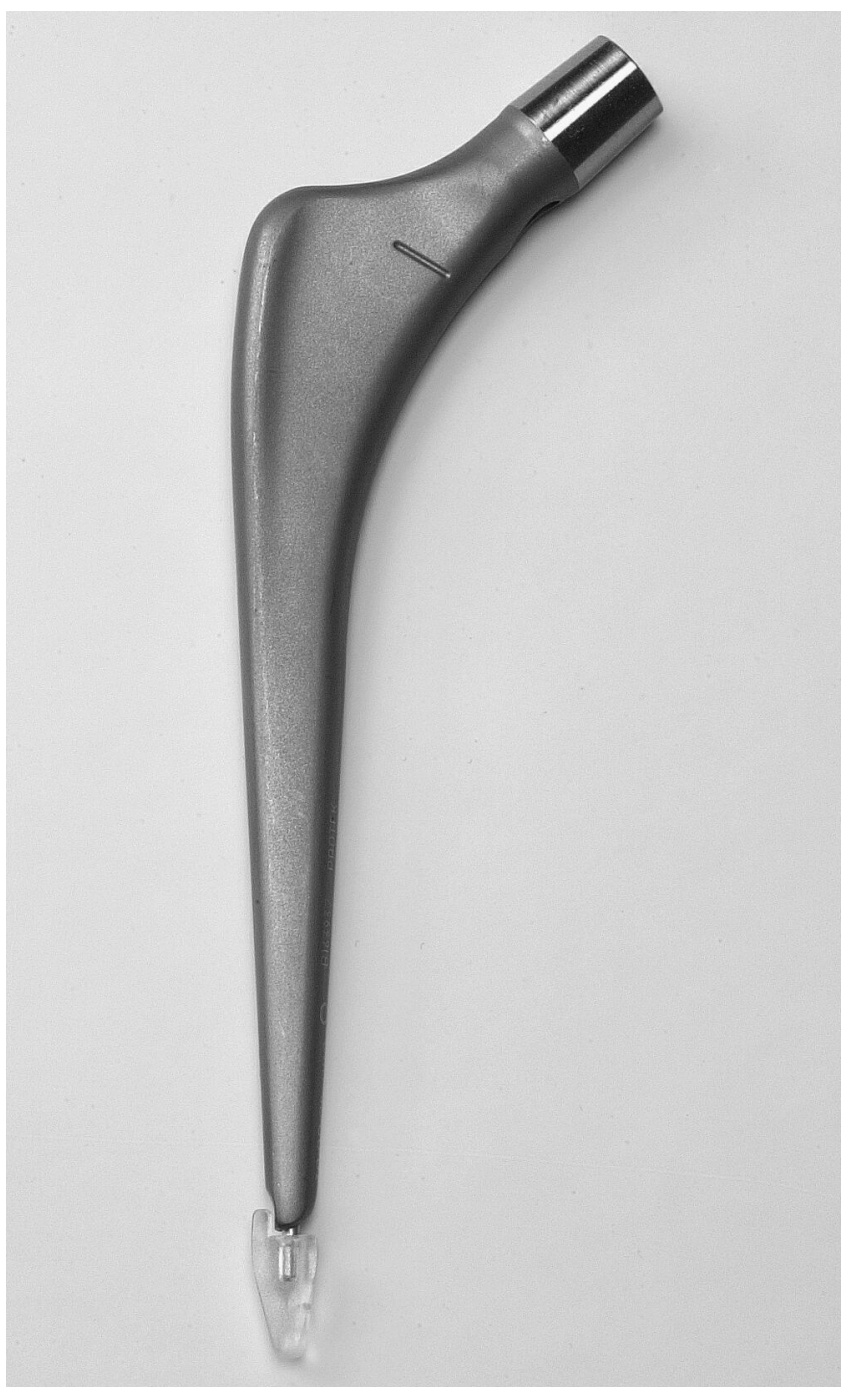

Fig. 1

Photograph of the MS-30 cemented femoral stem with the original centraliser.

original matt surface, especially with regard to radiolucency, osteolysis and subsidence.

\section{Patients and Methods}

The cemented MS-30 stem with a matt surface and an alumina-ceramic femoral head was introduced clinically in 1990. It was always fixed with Gentamicin-Palacos bone cement (Kulzer GmbH, Bad Homburg, Germany) containing gentamicin using a modern cementing technique.

Between January 1990 and December 1992, we implanted 124 stems (121 patients). The mean age of the patients at surgery was 67.6 years (36 to 89 ) for the 76 women and 67.3 years (49 to 86 ) for the 45 men. Of the 124 hips, the pre-operative diagnosis was osteoarthritis in $99(80 \%)$, avascular necrosis in $12(9 \%)$, dysplasia in seven $(6 \%)$, post-traumatic osteoarthritis in four $(3 \%)$ and rheumatoid arthritis in two $(2 \%)$.

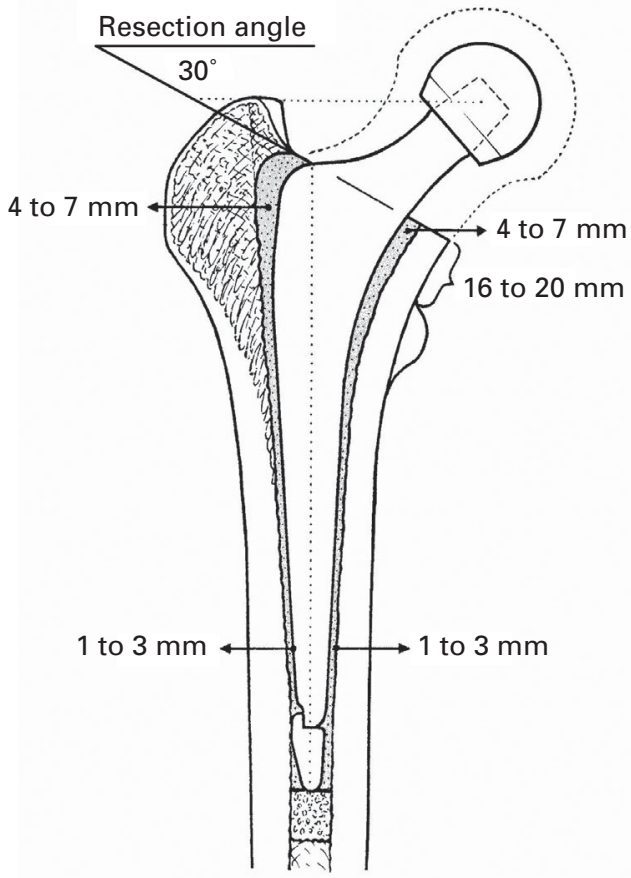

Fig. 2

Diagram of the MS-30 stem in the proximal femur indicating the optimum dimensions of the cement mantle and the $30^{\circ}$ angle of resection of the femoral neck.

Twenty-four patients (nine women, 15 men) had already undergone a contralateral THR with a Müller straight stem (Zimmer Ltd) before their initial surgery, while 14 (nine women, five men) subsequently had a contralateral procedure. The operations were performed by ten different surgeons of the Orthopaedic Department of the University of Basel, Switzerland, each with a different level of experience.

The right hip was treated in 58 cases and the left in 66. Twenty-seven patients $(22.3 \%, 14$ women, 13 men) died during the observation period. Nine (five women, four men) were either unable or unwilling to attend the followup at ten years and were interviewed by telephone. In all the THR was in situ. We reviewed 85 patients (56 women, 29 men; 88 hips) clinically and radiologically at ten years. No patient was lost to follow-up (Table I).

For the acetabular component, the Morscher press-fit cup (Zimmer, Fig. 3) was used in all patients. It was made of conventional ultra-high-molecular-weight polyethylene covered with an orientated titanium mesh (Sulmesh; Zimmer Ltd).

The patients underwent surgery in a supine position and all the implants except one were inserted through a lateral approach. No trochanteric osteotomy was performed. A rasp which was approximately $2 \mathrm{~mm}$ larger than the stem was used in order to provide the necessary space for the cement. The medullary canal was irrigated and packed with sponges until immediately before the introduction of the 
Table I. Details of the patients and implants

\begin{tabular}{lll}
\hline & Hips & Patients \\
\hline Number & 124 & 121 \\
Gender & & \\
$\quad$ Male & & 45 \\
$\quad$ Female & & 76 \\
Mean age at surgery in yrs (range) & 67.3 (49 to 86) \\
$\quad$ Men & & 67.6 (36 to 89) \\
$\quad$ Women & & 27 \\
Died by end of 2001 & 0 & 9 \\
Unable to attend follow-up & $88 \quad(71)$ & 0 \\
Lost to follow-up & 10.2 (70) \\
Number (\%) clinically and radiologically followed up & \\
Mean observation time in yrs (range) & 3 & \\
Bilateral, same stem (MS-30) & 2 & \\
Bilateral, one stage & 1 & \\
Bilateral, two stages & 25 & \\
Bilateral, other stem (Müller straight stem) & 17 & \\
Bilateral, one stage & 8 & \\
Bilateral, two stages & &
\end{tabular}

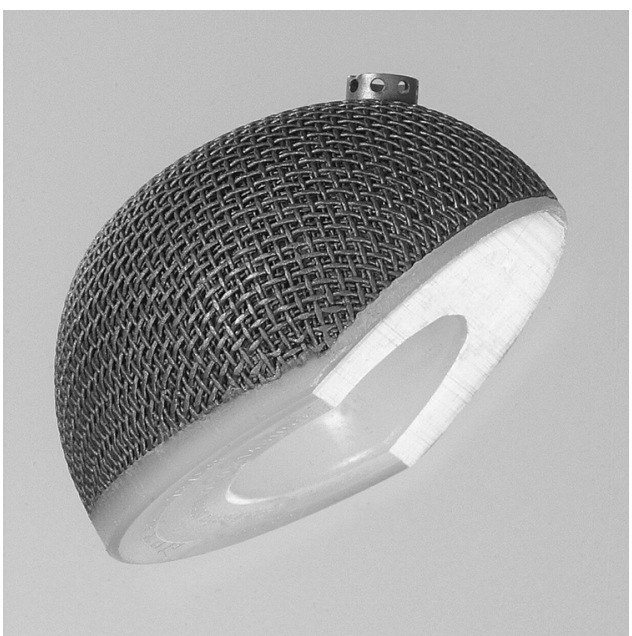

Fig. 3

Photograph of the uncemented Morscher press-fit cup.

cement. The cementing technique included the use of a cement gun, plugging of the distal femoral canal and pressurisation. The centraliser, designed to position the stem distally, is an integral part of the MS-30 stem. It serves to prevent contact between the implant and bone to avoid malalignment. The selected centraliser was usually one size larger than its respective stem. The femoral component was fixed with gentamicin-Palacos cement, according to the manufacturer's instructions. The mean length of surgery was 1.5 hours ( 1 to 3.5 ).

The peri-operative regimen was the same for all patients and included the use of antibiotics pre-operatively $(2 \mathrm{~g}$ Mandokef; Eli Lilly, Vernier, Switzerland) and prophylaxis against venous thrombosis (heparin $5000 \mathrm{U}$ and Sintrom (acenocoumarol; Novartis Consumer Health Schweiz AG, Bern, Switzerland) from the second post-operative day for six weeks). Post-operative rehabilitation consisted of mobilisation on the evening of the day of surgery or on the first post-operative day, partial weight-bearing for six weeks, and physiotherapy for three to six months.

The mean follow-up was for 10.2 years (8.3 to 12.1). Clinical assessment was in accordance with the International Documentation and Evaluation System (IDES) from the Institute of Documentation of the M. E. Müller Foundation in Bern, Switzerland. ${ }^{11}$ In addition, the Harris hip score was used for the evaluation of function. ${ }^{12}$

Radiological assessment. This included radiography of the pelvis, pubic symphysis and both hips. Osteolysis was defined as a new cystic lesion with endosteal scalloping and/ or migration, which had not been recorded on the postoperative radiograph taken at six weeks. ${ }^{13}$ The radiograph at the latest follow-up was examined for radiolucent lines (>2 $\mathrm{mm}$ ) at the cement-bone interface which were rated according to the Gruen zones in which they were found. ${ }^{6}$ Fixation of the acetabular component was also inspected for osteolysis and radiolucency in zones I to III of DeLee and Charnley. ${ }^{14}$

The stem was assessed for varus-valgus position. A varus-valgus malalignment was defined as a deviation from the longitudinal axis by more than $3^{\circ} .{ }^{15}$ The cement mantle was examined for fractures and subsidence within the mantle was measured as the distance between the upper circumference of the shoulder of the prosthesis and the sclerotic line above it. ${ }^{16}$ Ectopic ossification was assessed using the method of Brooker et al. ${ }^{17}$

Statistical analysis. The data were analysed and descriptive statistics calculated using Excel 95 (Microsoft Corp, Redmond, Washington). Survivorship was corrected according to Kaplan and Meier. ${ }^{18}$

\section{Results}

Clinical findings. The mean pre-operative Harris hip score improved from 73 (49 to 83 ) to 96 (72 to 100) post- 


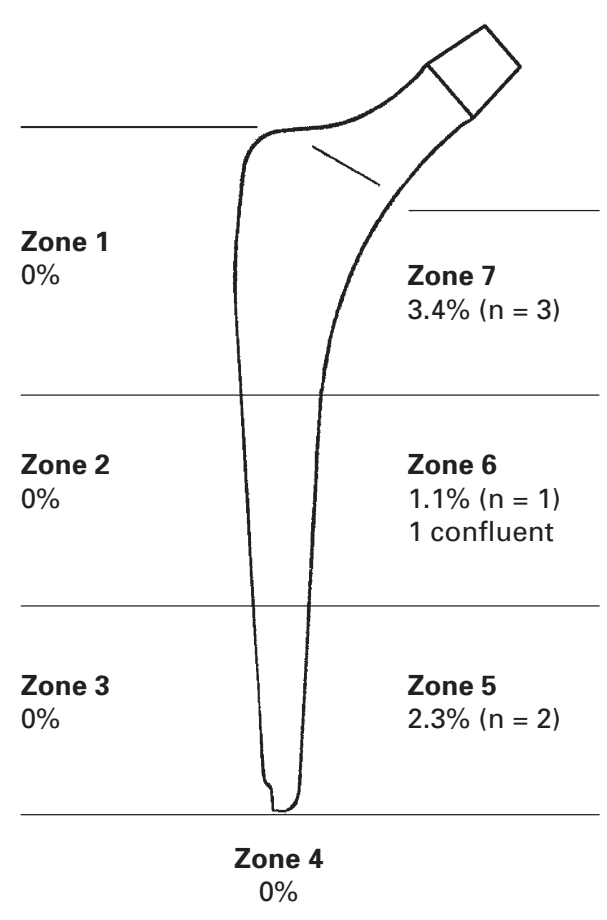

Fig. $4 a$

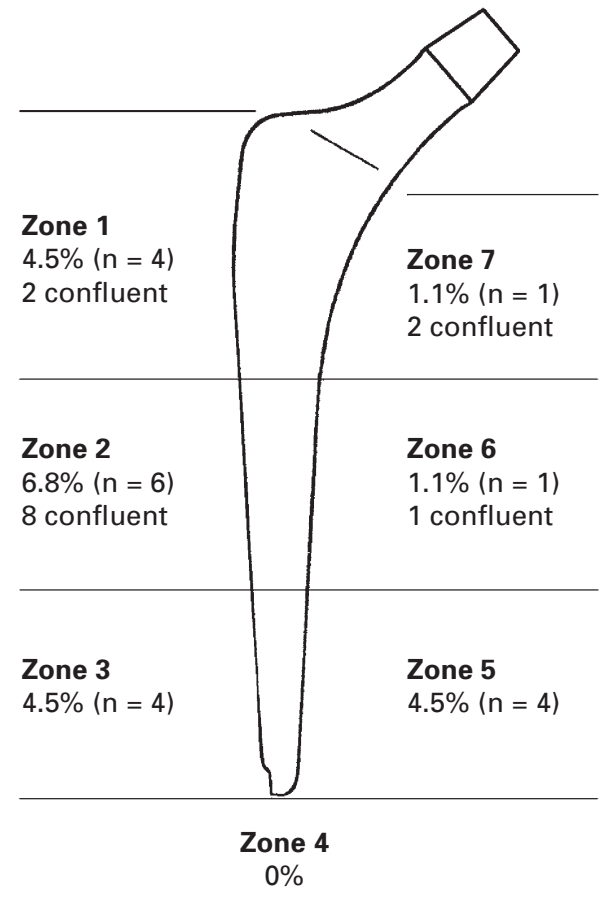

Fig. $4 \mathrm{~b}$

Diagrams of the incidence of a) focal osteolysis and b) radiolucency for the 88 femoral stems. Lesions which extended over two zones are described as 'confluent'.

operatively. The overall results were excellent in 73 hips $(83 \%)$, good in $12(14 \%)$ and fair in three $(3 \%)$. None of the surviving 25 patients with differing bilateral hip replacements (MS-30 and contralateral Müller straight stem) indicated a preference for either hip. Two patients with only a fair post-operative result and migration of 2 $\mathrm{mm}$ and $4 \mathrm{~mm}$ respectively, but with no osteolysis or radiolucency, had severe dysplasia of the hip and their pre-operative Harris hip scores were poor (53 and 56, respectively). One patient with a club foot had only a fair score of 72 .

Complications. Intra-operatively, there was one fracture of the greater trochanter and one of the proximal femur. These were stabilised with cerclage wire. Post-operatively, eight haematomas occurred. One dislocation was treated by closed reduction. There were no infections, no deep-vein thromboses and no deaths related to surgery.

Revisions. No revision, either of the MS-30 stems or of an acetabular component, was performed.

Radiological findings. Six osteolyses $(6.8 \%)$ and 20 radiolucencies $(22.7 \%)$ in one or more Gruen zones were found. Migration occurred in 22 hips, two (9.1\%) of which showed osteolysis and seven $(31.8 \%)$ radiolucent lines. In the 66 hips without migration, there was osteolysis in four $(6.1 \%)$ and radiolucent lines in $13(19.7 \%)$. The sites of the radiolucent lines and osteolyses are shown in Figure 4. In only one hip was a radiolucent line found to surround the cement mantle completely and the stem was therefore designated as radiologically loose. With the exception of this case, all subsidence took place within the cement mantle. Subsidence of less than $4 \mathrm{~mm}$ was found in 17 hips $(19.3 \%)$ and between $4 \mathrm{~mm}$ and $5 \mathrm{~mm}$ in five $(5.7 \%)$. No stem subsided more than $5 \mathrm{~mm}$ and no fracture of the cement was seen. Six hips with Brooker stage III peri-acetabular ossification were identified, but none had Brooker stage IV. One stem had a valgus displacement of $4^{\circ}$ and seven a varus displacement of between $4^{\circ}$ and $7^{\circ}$.

Acetabular component. There were no osteolyses and no revisions of the acetabular component. Three radiolucencies with a sclerotic line were observed, two in zone I and one in zone II.

\section{Discussion}

Past experience with the Exeter stem, reported by Ling, ${ }^{19}$ Howie, Middleton and Costi ${ }^{20}$ and Malchau and Herberts, ${ }^{21}$ showed a significantly higher revision rate for matt than for polished stems. A higher rate of revision with cemented, roughened titanium than with cemented smooth stems was also recently reported by Hinrichs et al. $^{22}$ By contrast in an earlier study, ${ }^{23}$ we found no difference between the two surface finishes of the MS-30 stem in regard to survivorship or subsidence, or to the incidence of osteolysis over a five-year period of observation. Spotorno et $\mathrm{al}^{24}$ reported a rate of revision for aseptic loosening of only $1 \%$ in a prospective, consecutive series of 197 hips with the polished FMS-30 stem (Zimmer Ltd) with a mean follow-up of 9.2 years. 


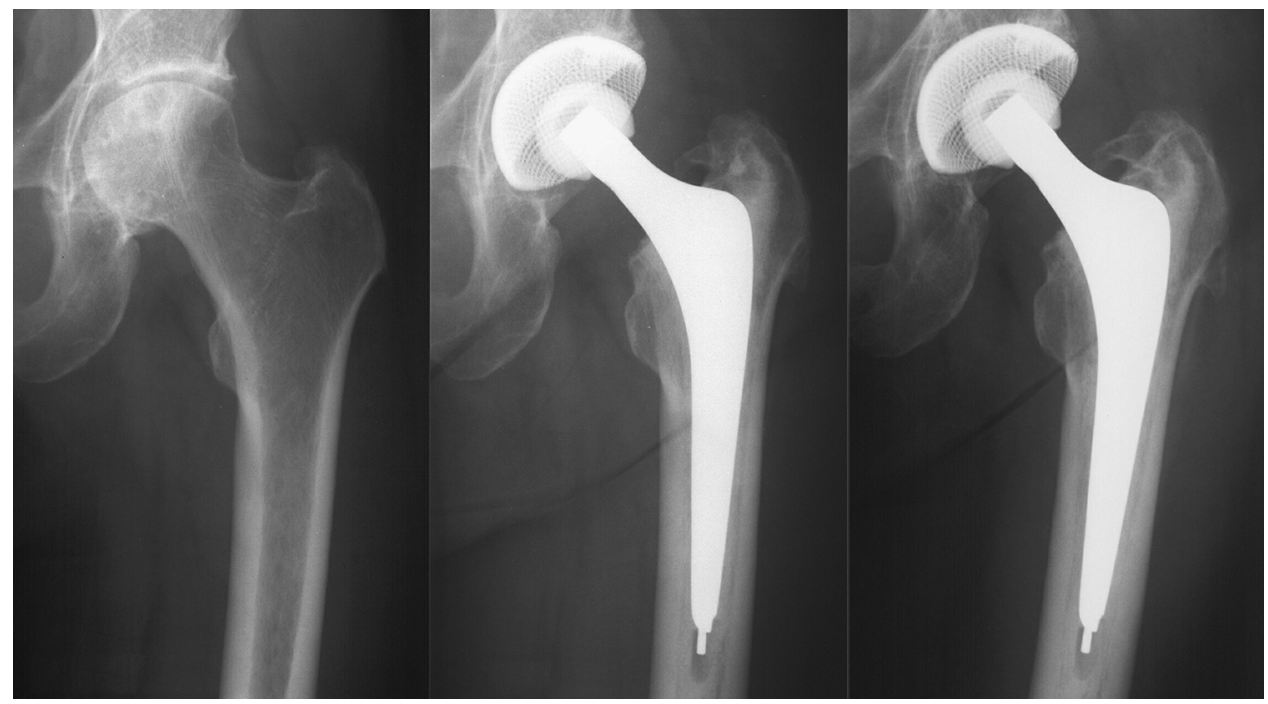

Fig. 5a

Fig. 5b

Fig. 5c

Radiographs showing a matt MS-30 stem with a Morscher press-fit cup in a 56-year-old woman with avascular necrosis a) pre-operatively, b) at six weeks post-operatively and c) after ten years. The patient has no pain and an excellent range of movement.

When designing the MS-30 stem, the main goal was to improve the quality of the cement mantle without abandoning the proven concept of a tapered design. The rationale to allow a tapered stem to subside recognises that subsidence within a cement mantle fails to correlate with pain ${ }^{25,26}$ and allows the stem to restabilise, a phenomenon which we call the "second line of defence". Subsidence is believed to reduce the tensile and shear loads of the cement, while increasing loading in compression.

Debonding, with subsidence of a tapered, collarless stem within the cement mantle, usually takes place within the first two years of surgery. ${ }^{24,27,28}$ Migration is faster in the first year, then becomes slower and stops after two years. In the present study, $25 \%$ of the MS-30 stems subsided up to $5 \mathrm{~mm}$ within two years of surgery. Osteolysis was seen in $2 \%$ and radiolucent lines in $8 \%$ after subsidence of between $2 \mathrm{~mm}$ and $5 \mathrm{~mm}$ had occurred. Continued subsidence after the second year, however, must be considered as definitive loosening. ${ }^{28-32}$

By contrast, studies of the surface roughness of the stem and creep-induced subsidence by Norman et al, ${ }^{33}$ suggested that subsidence of the stem is not important for the maintenance of a taper-lock, and creep-induced subsidence does not result in an increase in the normal stress patterns at the stem-cement interface.

Our study shows that the clinical survivorship for both the cemented MS-30 stem with a matt surface and the uncemented Morscher press-fit cup is excellent (Fig. 5). The slightly higher rate of osteolysis and radiolucency in cases of subsidence may be evidence for the superiority of a polished over a matt surface for tapered stems, as has been shown for the Exeter component. ${ }^{20,21,28,29}$ Further observations of patients with a matt-surfaced MS-30 stem are clearly indicated although it has been recently withdrawn from the market. This recommendation for further observation is supported by a number of studies which report that polished-surface cemented stems perform better than roughened stems and that subsidence of a polished stem is advantageous. ${ }^{20,21,28,29}$

No benefits in any form have been received or will be received from a commercial party related directly or indirectly to the subject of this article.

\section{References}

1. Morscher EW, Spotorno L, Mumenthaler A, Frick W. The cemented MS-30 stem. In: Morscher EW, ed. Endoprosthetics. Berlin, etc: Springer, 1995:211-19.

2. Miller J, Johnson A. Advances in cementing techniques in total hip arthroplasty. In: Stilwell WT, ed. The art of total hip arthroplasty. New York: Grunde \& Stratton, 1987: 277-92.

3. Ebramzadeh E, Sarmiento A, McKellop HA, Linas A, Gogan W. The cement mantle in total hip arthroplasty. J Bone Joint Surg [Am] 1994;76-A:77-87.

4. Draenert K, Draenert Y. Die adaptation des knochens an die deformation durch implantate: strain-adaptive bone remodelling. Munich: Art \& Science, 1992.

5. Markolf KL, Amstutz HC. A comparative experimental study of stresses in femoral total hip replacement components: the effects of prosthesis orientation and acrylic fixation. J Biomech 1976;9:73-9.

6. Gruen TA, McNeice GM, Amstutz HC. "Modes of failure" of cemented stem-type femoral components: a radiographic analysis of loosening. Clin Orthop 1979;141:17-27.

7. Wroblewski BM, Siney PD, Fleming PA, Bobak P. The calcar femorale in cemented stem fixation in total hip arthroplasty. J Bone Joint Surg [Br] 2000;82-B: $842-5$

8. Estok DM II, Orr TE, Harris WH. Factors affecting cement strains near the tip of a cemented femoral component. J Arthroplasty 1997;12:40-8.

9. Freeman MAR. Why resect the neck? J Bone Joint Surg [Br] 1986;68-B:346-9.

10. Nunn D, Freeman MAR, Tanner KE, Bonfield W. Torsinal stability of the femoral component of hip arthroplasty: response to an anteriorly applied load. J Bone Joint Surg [Br] 1989;71-B:452-5

11. Johnston RC, Fitzgerald RH, Harris WH, et al. Clinical and radiographic evaluation of total hip replacement: a standard system of terminology for reporting results. J Bone Joint Surg [Am] 1990;72-A:161-8.

12. Harris WH. Traumatic arthritis of the hip after dislocation and acetabular fracture: treatment by mold arthroplasty. J Bone Joint Surg [Am] 1969;51-A:737-55.

13. Joshi RP, Eftekhar NS, McMahon DJ, Nercessian OA. Osteolysis after Charnley primary low-friction arthroplasty: a comparison of two matched paired groups. J Bone Joint Surg [Br] 1998;80-B:585-90 
14. DeLee JG, Charnley J. Radiological demarcation of cemented sockets in hip replacement. Clin Orthop 1976;121:20-33.

15. Kelly AJ, Lee MB, Wong NS, Smith EJ, Learmonth ID. Poor reproducibility in radiographic grading of femoral cementing technique in total hip arthroplasty. J Arthroplasty 1996;11:525-8.

16. Acklin YP, Berli BJ, Frick W, Elke R, Morscher EW. Nine-year results of Müller cemented titanium straight stems in total hip replacement. Arch Orthop Trauma Surg 2001:121:391-8

17. Brooker AF, Bowerman JW, Robinson RA, Riley LH Jr. Ectopic ossification following total hip replacement: incidence and a method of classification. J Bone Joint Surg [Am] 1973;55-A:1629-32.

18. Kaplan EL, Meier P. Nonparametric estimation from incomplete observations. J Am Statist Assn 1958:53:457-81.

19. Ling RS. The use of a collar and precoating in cemented femoral stems is unneces sary and detrimental. Clin Orthop 1992;285:73-83.

20. Howie DW, Middleton RG, Costi K. Loosening of matte and polished cemented femoral stems. J Bone Joint Surg [Br] 1998;80-B:573-6.

21. Malchau H, Herberts P. Prognosis of total hip replacement: revision and re-revision rate in THR: a revision risk study of 148, 359 primary operations [abstract]. Procs Annual Meeting American Association of Orthopaedic Surgeons, 1998.

22. Hinrichs F, Kuhl M, Boudriot U, Griss P. A comparative clinical outcome evaluation of smooth (10-13 year results) versus rough surface finish (5-8 year results) in an otherwise identically designed cemented titanium alloy stem. Arch Orthop Trauma Surg 2003;123:268-72.

23. Berli B, Elke R, Morscher EW. The cemented MS-30 stem in total hip replacement matte versus polished surface: minimum of five years of clinical and radiographic results of a prospective study. In: Winters GL, Nutt MJ, eds. Stainless stee/s for medical and surgical applications, ASTM STP 1438. West-Consho-hocken, Pennsylvania: ASTM International, 2003:249-61.
24. Spotorno L, Grappiolo G, Penenberg BL, Burastero G. Eight to eleven year review of hybrid THA using a polished femoral stem and cementless titanium acetabulum [abstract]. Procs American Association of Orthopaedic Surgeons, 2002.

25. Räber DA, Czaja S, Morscher EW. Fifteen-year results of the Müller CoCrNiMo straight stem. Arch Orthop Trauma Surg 2001;121:38-42.

26. Wilson-MacDonald J, Morscher E. Comparison between straight- and curvedstem Müller femoral prostheses: 5- to 10-year results of 545 total hip replacements. Arch Orthop Trauma Surg 1989;109:14-20.

27. Alfaro-Adrián J, Gill HS, Murray DW. Should total hip arthroplasty femoral components be designed to subside?: a radiostereometric analysis study of the Charnley Elite and Exeter stems. J Arthroplasty 2001;16:598-606.

28. Alfaro-Adrián J, Gill HS, Murray DW. Cement migration after THR: a comparison of Charnley elite and Exeter femoral stems using RSA. J Bone Joint Surg [Br] 1999; 81-B:130-4.

29. Søballe K, Toksvig-Larson S, Gelinek J, et al. Migration of hydroxyapatite coated femoral prostheses: a roentgen stereophotogrammetric study. J Bone Joint Surg [Br] 1993;75-B:681-7.

30. Harris WH, McCarthy JC, O'Neill DA. Femoral component loosening using contemporary techniques of femoral cement fixation. J Bone Joint Surg [Am] 1986;68-A 1064-6.

31. Kärrholm J, Snorrason F. Subsidence, tip and hump micromovement of noncoated ribbed femoral prostheses. Clin Orthop 1993;287:50-60.

32. Fowler JL, Gie GA, Lee AJC, Ling RSM. Experience with the Exeter total hip replacement since 1970. Orthop Clin North Am 1988;19:477-89.

33. Norman TL, Thyagarajan G, Saligrama VC, Gruen TA, Blaha JD. Stem surface roughness alters creep induced subsidence and "taper-lock" in a cemented femoral hip prosthesis. J Biomech 2001;34:1325-33. 